\title{
Interactive comment on "A 30-meter resolution dataset of China's urban impervious surface area and green space fractions, 2000-2018" by Wenhui Kuang et al.
}

\section{Anonymous Referee \#2}

Received and published: 10 August 2020

The comment was uploaded in the form of a supplement:

https://essd.copernicus.org/preprints/essd-2020-107/essd-2020-107-RC2-

supplement.pdf

Interactive comment on Earth Syst. Sci. Data Discuss., https://doi.org/10.5194/essd-2020-107, 2020. 